\section{Book reviews in the electronic age}

Doctors, perhaps more than any other professionals, need to keep abreast of their subject. They need every encouragement to do this. Crown et al (2000) gave us a valuable reminder of the importance of book reviews in stimulating interest in new publications. As a reader, I enjoy a mixture of reviews, from reviews of leading textbooks to a review of a biography of Iris Murdoch, who suffered from dementia (Garner, 2000). Book reviews are a valuable part of the Journal.

But technology has moved on and the printed word is no longer the only way in which doctors obtain information or exchange ideas. The internet is increasingly becoming the first recourse for doctors seeking information. It is also being used more and more by patients, who come to the doctor clutching triumphantly printouts of material downloaded from the web. A patient may not always fully understand the latest paper he or she has found on the website of an American university, but will soon lose confidence in the doctor if he or she is entirely unaware of it.

There are hundreds, if not thousands, of medical websites, and the busy practitioner needs guidance as to which are worthwhile and which are not. It would be an immense service to readers if the Book Review Editors could extend the valuable work they do to encompass the new medium of the internet.

Crown, S., Lee, A., Ramsay, R., et al (2000) And now the book reviews ... British journal of Psychiatry, $\mathbf{1 7 7}$, 388-389.

Garner, J. (2000) When the badgers broke in. Old Age Psychiatrist, Autumn, 7-8.

A.Thompsell Maudsley Hospital, Denmark Hill, London SE5 8AZ

We were pleased to see that Crown et al (2000) are considering bringing us into the 21 st century with their suggestion regarding the review of websites. We feel that the proliferation of unreviewed information is a potential source of patient distress and general confusion. One way forward would be for authorities (e.g. a national medical association) to review sites and give 'seals of approval'. There are several rating scales for websites, all with varying quality criteria and little testing for reliability and validity (Jadad \& Gagliardi, 1998). There are also concerns about possible litigation if a reviewing authority gives a bad review, for example, and the site loses traffic as a result (Terry, 2000). Although "Rating the quality of medical websites may be impossible" (Delamothe, 2000), we think it is useful to have some framework within which individuals can think about websites and compare their value for their own particular information needs.

We have been developing a standardised format to assess websites, looking at two main areas in a more qualitative way. First, ease of operation and layout, scored on a visual analogue scale. Second, an assessment of content under such headings as quality issues, provenance, and frequency of updates. The general public and the media should have some guidance as to which websites should be taken seriously and which should be avoided at all costs. When our project is complete we will seek publication conventionally and on our own website (www.ask-a-psychiatrist.co.uk).

Few people have access to psychiatric textbooks and libraries, but access to the web is likely to become almost universal in the developed world over the next few years. We should take advantage of this opportunity to promote the understanding of mental health issues by encouraging people to access reliable sources of information.

Crown, S., Lee, A., Ramsay, R., et al (2000) And now the book reviews. . . British Journal of Psychiatry, 177, 388-389.

Delamothe, T. (2000) Quality of websites: kitemarking the west wind. British Medical Journal, 32I, 843-844.

Jadad, A. R. \& Gagliardi, A. (1998) Rating health information on the internet. Journal of the American Medical Association, 279, 611-614.

Terry, N. P. (2000) Rating the "raters": legal exposure of trustmark authorities in the context of consumer health informatics. Journal of Medical Internet Research, 2, el8 (http://www.jmir.org/2000/3/el8/index.htm).

A. Gray, S. Lamerton St Anne's Orchard, Psychiatric Day Hospital, Link Top, Worcester Road, Malvern, Worcester WRI4 IEZ

\section{Evolutionary theory and psychiatry}

While we welcome Abed's (2000) editorial and endorse the arguments presented in it, we feel that it gives an inadequate account of the important British contribution to the burgeoning new discipline of evolutionary psychiatry. Instead, it leaves one with the impression that Darwinian psychiatry is largely an American achievement and that Abed and Marks are the only homegrown contributors to it. This is unjust, as the application of evolutionary theory to psychiatric disorders began in this country 40 years ago at a time when American psychiatry was still in thrall to psychoanalysis and behaviourism. Bowlby's (1958) classic paper on the phylogeny of the child's bond to its mother and his life's work on the consequences of rupturing that bond for later psychopathology were seminal contributions to the development of the new evolutionary paradigm, as were Price's papers in the 1960s on social dominance and the evolution of mental illness (e.g. Price, 1967; further references in Stevens \& Price, $2000 a$ ). Since then, British psychologists and psychiatrists have contributed as much to this fascinating field of enquiry as our American colleagues, whom Abed cites. In particular, we would draw attention to the work of Crow (1995) on the Darwinian approach to the origins of psychosis, Gilbert (1992) on depression and the evolution of powerlessness, and our own work on the evolutionary basis of the major neurotic, 'functional' psychotic, and reproductive disorders (Stevens \& Price, 20000a), and the phylogeny of schizophrenia (Stevens $\&$ Price, 2000b). In addition, significant work has been published by Archer (1992) on ethology and human development, Bailey (1987) on human palaeontology, and Birtchnell (1993) on how humans relate.

A major criticism advanced against 'adaptionist' explanations of psychiatric disorders is that they are untestable and therefore of little use; this is untrue. We have responded to this criticism by providing testable predictions based on evolutionary insights (Stevens \& Price, 2000a. pp. 258-274). As Abed rightly suggests, scientific method requires "a theoretical framework that generates testable predictions", that "demands what questions to ask" and that "suggests what avenues of research are likely to bear fruit". Evolutionary psychiatry is now sufficiently advanced in this country for this programme to be implemented. Unfortunately, an uninformed reader would not have gathered this from Abed's editorial.

Abed, R. T. (2000) Psychiatry and Darwinism. Time to reconsider? British Journal of Psychiatry, 177, I-3.

Archer, J. (1992) Ethology and Human Development New York: Harvester/Wheatsheaf.

Bailey, A. K. (1987) Human Paleopsychology: Applications to Aggression and Pathological Processes. Hove: Lawrence Erlbaum.

Birtchnell, J. (1993) How Humans Relate: A New Interpersonal Theory. Westport, CN: Praeger. 